\title{
Nitric Oxide Electrochemical Sensors Based on Hybrid Films of Conducting Polymers and Metal Phtalocyanines
}

\author{
M.C. Miras, A. Badano, M.M. Bruno, C. Barbero * \\ Departamento de Química, Universidad Nacional de Rio Cuarto, \\ Agencia Postal No 3, 5800-Rio Cuarto, Argentina.
}

Received 30 December 2002; accepted in revised form 25 February 2003

\begin{abstract}
Hybrid films of poly(o-aminophenol) and nickel sulfonated phtalocyanine are produced by electrochemical polymerization of o-aminophenol in the presence of the metal complex. The irreversible incorporation of the metal complex into the hybrid films is tested using reflectance infrared spectroscopy. Electrodes modified with poly(oaminophenol) alone and the hybrid film show a higher electrocatalytic activity, for NO oxidation, than the base substrate electrode (glassy carbon). The hybrid films show higher currents and lower oxidation overpotential. The oxidation peak current is linear with concentration up to $200 \mu \mathrm{M}$ of $\mathrm{NO}$.
\end{abstract}

Keywords: nitric oxide, sensors, poly(o-aminophenol), phtalocyanine, hybrid films.

\section{Introduction}

Nitric Oxide (NO) has acquired great relevance as biological analyte due to its role as cell signalling molecule, involved in the immunity regulation, defence mechanism and neurotransmission[1]. Additionally, NO has a role in the action of nitrite as a food preserver. A very useful method to monitor NO and related molecules consists in the electrochemical measurement of $\mathrm{NO}$ oxidation to higher oxides[2]. In such an use, conventional electrode materials (e.g. platinum) show low sensitivity and selectivity. A viable alternative is the use of carbon electrodes modified with electroactive films. The electrocatalysis on the films would allow to increasing both sensitivity and selectivity. The method could be

\footnotetext{
* Corresponding author. E-mail address: cbarbero@exa.unrc.edu.ar
} 
used to follow the $\mathrm{NO}$ concentration in real time (seconds), giving a time resolved information about metabolic functions. Additionally, using ultramicroelectrodes, it is possible to monitor NO concentration inside the cell.

While several electrocatalysts have been used, a polymer produced by electroxidation of nickel hydroxiphenylporphyrin has shown clear electroactivity. Development of stable NO sensors is important for its use in clinical therapy [3]. It has been shown that the nickel porphyrine polymer losses $\mathrm{Ni}$ in the testing media [4]. On the other hand, phtalocyanines are very stable materials, with electrocatalytic effects towards different systems [5]. Phtalocyanines form complexes with metal atoms more stable than porphyrines and have been used successfully in more aggressive media [6]. Metal phtalocyanines have been incorporated into polyaniline films for oxygen electrocatalysis [7].

In the present communication, we describe the development of NO sensors based on hybrid films of poly(o-aminophenol) and Ni sulfonated phtalocyanine.

Poly(o-aminophenol) films can be produced by electrochemical polymerization of o-aminophenol [8]. The films have been used as conductive support of enzymes in biosensors [9] and a low electrocatalytic activity for oxygen reduction has been reported [10].

\section{Experimental}

All solutions were produced using ultrapure (Millipore) water and analytical quality reagents. 2-aminophenol (Fluka, purum) was twice recrystallized from ethyl acetate, once from benzene and dried under vacuum. All potentials are reported against calomel saturated electrode (SCE) as reference.

\section{Nitric oxide production and standardization}

NO was produced by reaction of nitrite with iodide in acid media. The obtained gas was bubbled trough a $0.1 \mathrm{M} \mathrm{KOH}$ solution to retain $\mathrm{NO}_{2}$ and acid droplets. The phosphate buffer $(\mathrm{pH}=7)$ used to prepare stock solutions was degassed previously by bubbling $\mathrm{N}_{2}$ for 1 hour. The solutions were stored at $4{ }^{\circ} \mathrm{C}$. The concentration of NO in stock solutions was evaluated by colorimetry of the azo 
dye formed by coupling of the diazonium salt of sulfanilic with 1-naphtylamine [11]. The diazonium salt is formed by reaction of the sulfanilic acid with NO.

During measurements the cell was maintained under a blanket of $\mathrm{N}_{2}$ to avoid oxidation by oxygen of the NO in solution. The peak current of successive voltammograms differs in less than $3 \%$ assuring that NO concentration was constant during measurements.

\section{Polymerization}

Poly(o-aminophenol) films were produced by cycling the base electrode ( $\mathrm{Pt}$ or GC) between -0.25 and $0.7 \mathrm{Vsce}$ at $50 \mathrm{mV} / \mathrm{s}$ in a solution $0.05 \mathrm{M}$ of oaminophenol in $0.5 \mathrm{M} \mathrm{HClO} 4$. To incorporate the metal complex, sulfonated nickel phtalocyanine (Fluka, puriss) was added to the solution in a $10 \mathrm{mM}$ concentration.

\section{Electrochemistry}

The electrochemical experiments were performed using a GAMRY PC4/750 potentiostat controlled by a personal computer. A conventional three electrode cell was used with a Pt wire as counter electrode and a saturated calomel electrode as reference. The working electrode materials were either GC or Pt. The GC electrodes were GC disks made by pressing a $3 \mathrm{~mm}$ diameter glassy carbon rod inside a Teflon tube $(2.95 \mathrm{~mm}$ internal diameter). The electrode surface was polished with alumina powder (down to $1 \mu \mathrm{m}$ ). The electrode used for infrared reflectance was built with a $0.5 \mathrm{~mm}$ thick $\mathrm{Pt}$ plate $(1 \mathrm{x} 1 \mathrm{~cm}$ size $)$, mirror polished.

\section{Reflection-absorption FTIR spectroscopy}

Measurements of the FTIR spectra of polymer films onto electrodes were made by ex-situ reflection-absorption. The measurements were carried out in a SpectraTech specular reflectance accessory with an incidence angle of $70^{\circ}$. The polymer films were deposited on polished Pt plates and a polished Pt plate was 
used to record the background spectrum. The measurements were carried out in a Nicolet Impact 400 FTIR spectrophotometer with a resolution of $1 \mathrm{~cm}^{-1}$ and 200 scans. To improve the sensitivity to surface species[12], p-polarized radiation was used.

\section{Results and Discussion}

Cyclic voltammograms, taken during electrochemical deposition of a typical hybrid film, are shown in Fig. 1.

An oxidation peak for the monomer (o-aminophenol) could be clearly seen at ca. 0.535 Vsce. After several cycles, a new pair of redox peaks at ca. 0.08 Vsce (anodic) and -0.01 Vsce (cathodic) could be observed. The peak system appears in a potential that corresponds to the redox response of poly(o-aminophenol) [13]. The oxidation peak of the monomer decreases in intensity with cycling, indicating that the growth is not autocatalytic as in the case of polyaniline [14]. On the other hand, the current due to the redox response of the film increases with cycling due to the increase of redox charge during growth of the polymer layer.

The polymerization in presence of the metal complex is faster than with oaminophenol alone probably due to electrocatalysis of the metal complex or a template effect of the sulfonic groups. After several cycles $(>50)$ a film of poly(o-aminophenol)/sulfonated nickel phtalocyanine (poAP/NiSuPh) is deposited on the electrode. The modified electrode, tested in a monomer free solution $(0.5 \mathrm{M} \mathrm{HClO} 4)$, shows only a peak system at ca. $0.0 \mathrm{Vsce}$. The polymer itself shows no redox response in $\mathrm{pH} 7$ solution.

The incorporation of the metal complex into the polymer film was tested by exsitu reflection-absorption FTIR spectroscopy. 


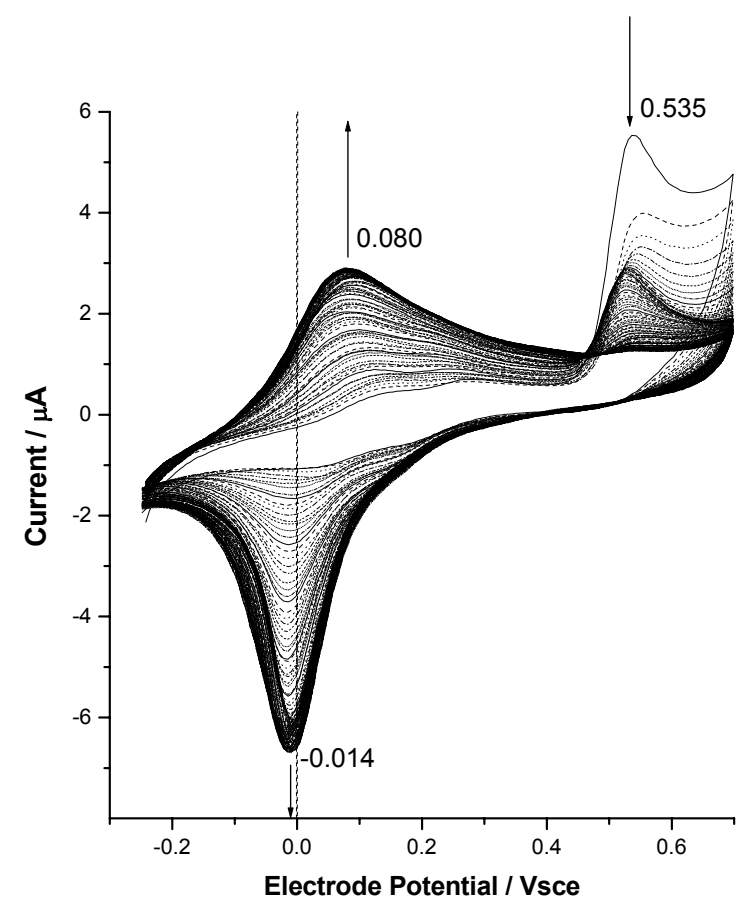

Figure 1. Cyclic voltammograms of a GC electrode during polymerization of oaminophenol in presence of sulfonated nickel phtalocyanine. Solution $=0$-aminophenol $(0.05 \mathrm{M})$, nickel sulfonated phtalocyanine $(0.01 \mathrm{M}), \mathrm{HClO}_{4}(0.5 \mathrm{M})$. Scan rate $=50$ $\mathrm{mV} / \mathrm{s} . \mathrm{A}=0.071 \mathrm{~cm}^{2}$.

In Fig. 2.a) is shown the FTIR spectrum of a polymer film produced from oaminophenol with the metal complex in the solution. The spectrum of poly(oaminophenol) is shown for comparison (Figure 2.b). Both spectra show infrared bands which could be assigned to the polymer backbone [15]: $1582 \mathrm{~cm}^{-1}$ (quinoid ring or $\mathrm{C}=\mathrm{N}$ stretching in the phenozazine units), $1511 \mathrm{~cm}^{-1}(\mathrm{C}=\mathrm{C}$ st. in aromatic rings), $1294 \mathrm{~cm}^{-1}$ (C-N stretching in the cyclic secondary aromatic amine (leucophenoxazine) units), $1195 \mathrm{~cm}^{-1}$ (C-H breathing in the quinonimine ring) and $860 \mathrm{~cm}^{-1}$ (aromatic C-H stretching). The results agree with previous assignment [16] and recent data obtained using in-situ reflectance FTIR [17].

The hybrid film, produced with the metal complex in solution, reveals new bands at 1063 and $1030 \mathrm{~cm}^{-1}$, which are assigned to the stretching of the sulfonate group [18]. The presence of those bands confirms that the complex is 
incorporated into the polymer film. The bands are retained after cycling in a solution without the complex, even at $\mathrm{pH} 7$.

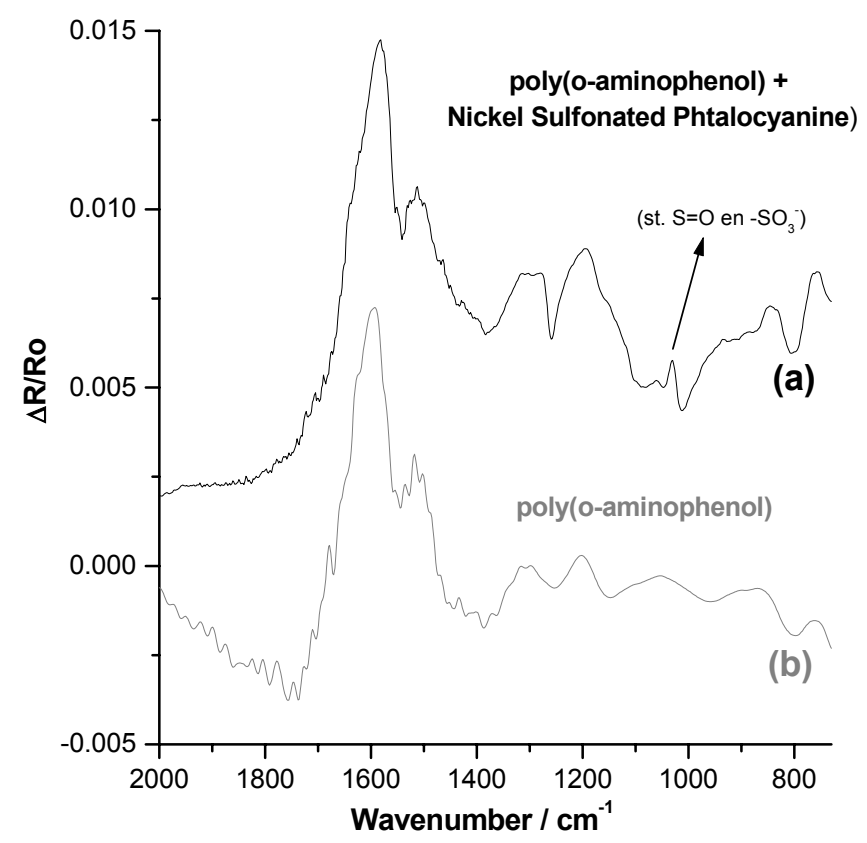

Figure 2. FTIR spectra of: (a) a poly(o-aminophenol)/nickel sulfonated phtalocyanine film on Pt (black line); (b) poly(o-aminophenol) film on Pt (grey line). Measurements with 200 scans, $1 \mathrm{~cm}^{-1}$ resolution, p-polarized light.

Electrodes modified with the polymer layers were tested for NO electrochemical oxidation (Fig. 3). The peak at ca. $0.95 \mathrm{~V}$ corresponds to the $\mathrm{NO}$ oxidation and increases with $\mathrm{NO}$ concentration. As it can be seen both poAP and poAP/NiSuPh films present higher electrotalytic activity for NO oxidation than the base substrate (GC). The oxidation current, in the electrode modified with the complex, is higher and the oxidation overpotential is lower indicating that the $\mathrm{Ni}$ complex incorporated into the hybrid film could electrocatalyze NO oxidation. Measuring the peak current is possible to determine the concentration of NO in the solution. The peak current is linear with concentration up to $200 \mu \mathrm{M}$ (Fig. 4). 


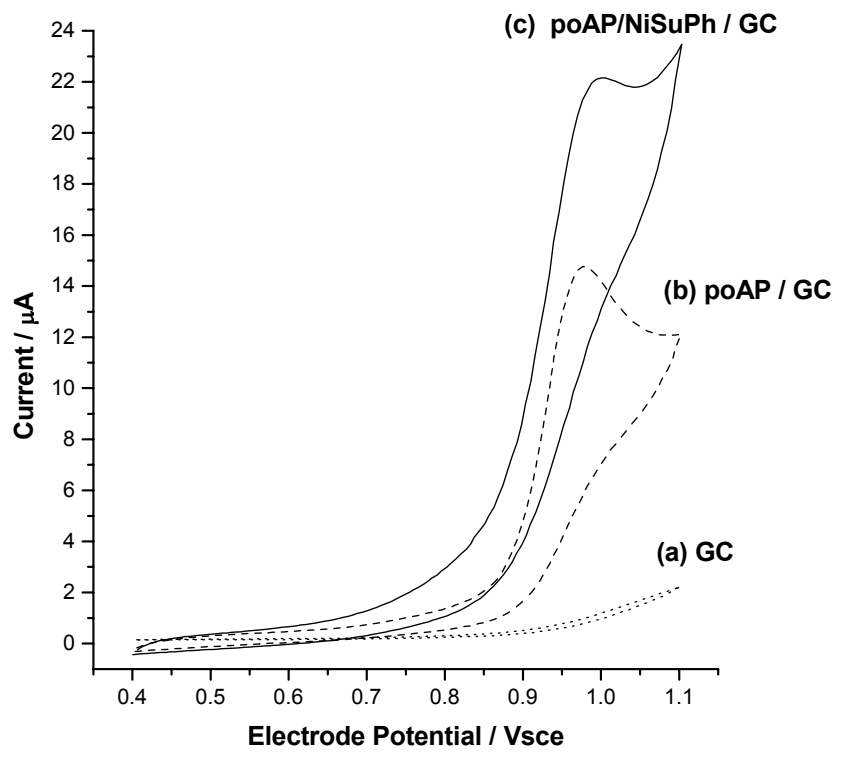

Figure 3. Cyclic voltammograms for NO oxidation of: (a) a bare GC electrode, (b) a poly(o-aminophenol) modified electrode, (c) a poly(o-aminophenol)/nickel sulfonated phtalocyanine modified electrode in a NO solution $([\mathrm{NO}]=190 \mu \mathrm{M}, \mathrm{pH}=7) . \mathrm{A}=0.071$ $\mathrm{cm}^{2}$. Scan rate $=10 \mathrm{mV} / \mathrm{s}$.

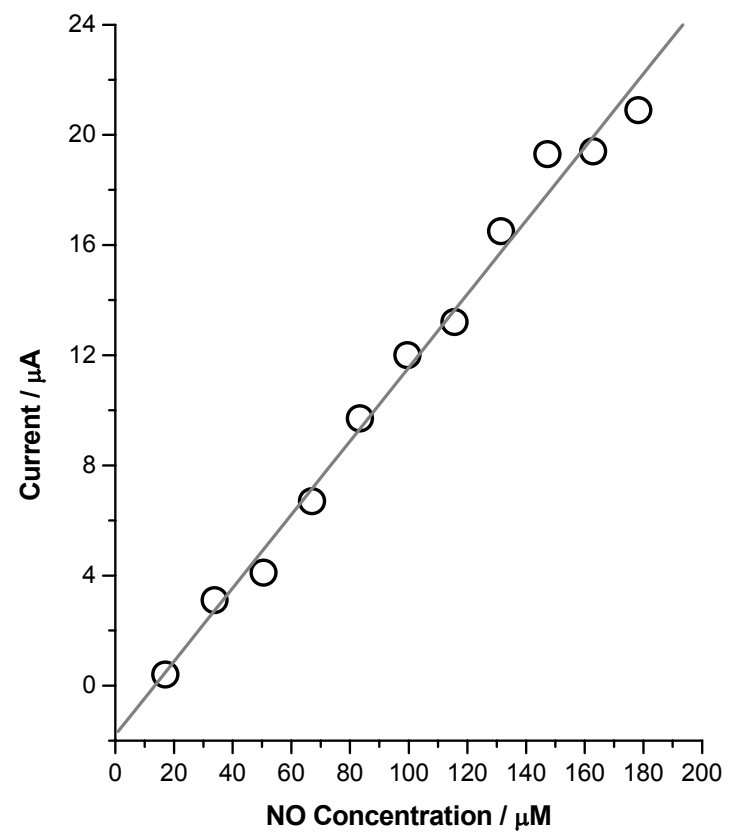

Figure 4. Relationship between the peak current and NO concentration during oxidation of NO on a poly(o-aminophenol)/nickel sulfonated phtalocyanine modified electrode. Same conditions as in Fig. 3. 


\section{Conclusions}

A hybrid modified electrode could be easily produced by electropolymerization of o-aminophenol in the presence of sulfonated nickel phtalocyanine. The metal complex is incorporated into the polymer film as shown by reflectance FTIR. The film is stable in acidic and neutral solutions. The modified electrode presents electrocatalysis of NO oxidation, with a linear response up to $200 \mu \mathrm{M}$ of NO. Application of the modified electrodes for the electrocatalysis of other analytes such as $\mathrm{O}_{2}$ and $\mathrm{NO}_{2}^{-}$is currently explored in our laboratory.

\section{Acknowledgements}

The financing of the work by FONCYT, CONICET, Agencia Córdoba Ciencia, Fundacion Antorchas and SECYT-UNRC is gratefully acknowledged. C. Barbero is a permanent research fellow of CONICET. M. Bruno thanks FONCYT for a graduate research fellowship. A. Badano thanks EDUMAT for an undergraduate research fellowship.

\section{References}

1. R.M.J. Palmer, A.G. Ferrige, S. Moncada, Nature 327 (1987) 524; L. Lancaster Jr. Ed, "Nitric Oxide, Principles and Actions" Academic Press, San Diego, 1996.

2. T. Malinski, Z. Taha, Nature 358 (1992) 676.

3. H. Tsukahara, Biochem. Biophys. Res. Comms. 193 (1993) 722.

4. A. Ciszewski, E. Kubaszewski, M. Lozynski, Electroanalysis 8 (1996) 293.

5. O. Raveh, N. Peleg, A. Bettelheim, I. Silberman, J. Risphon, Bioelectrochem. \& Bioenerget. 43 (1997) 19; I. Rosen-Margalit, A. Bettelheim, J. Risphon, Anal. Chim. Acta 281 (1993) 327; P. Skadal, Talanta 38 (1991) 1077.

6. L. Otero, H. Osoro, W. Li, M.A. Fox, J. Porphyrins and Phtalocyanines 2 (1998) 123, and references therein.

7. A. El Hourch, S. Belcadi, P. Moisy, P. Crouigneau, J.-M. Léger, C. Lamy, J. Electroanal. Chem. 339 (1992) 1; C. Coutanceau, P. Crouigneau, J.M. Léger and C. Lamy, J. Electroanal. Chem. 379 (1994) 389.

8. C. Barbero, J.J. Silber, L. Sereno, J. Electroanal. Chem. 291 (1990) 81. 
9. M.A. Valdes Garcia, P. Tuñon Blanco, A. Ivaska, Electrochim. Acta 43 (1998) 3533.

10. T. Ohsaka, T. Watanabe, F. Kitamura, N. Oyama, K. Tokuda, J. Chem. Soc., Chem. Commun. (1991) 1072.

11. D.A. Skoog, D.M. West, "Principles of Instrumental Analysis", 2nd ed., Saunders College, New York, 1990.

12. B. Beden, C. Lamy, "Infrared Reflectance Spectroscopy" in "Spectroelectrochemistry", R.J. Gale, Ed., Plenum Press, New York, 1988.

13. C. Barbero, J.J. Silber, L.Sereno, J. Electroanal. Chem. 263 (1989) 333.

14. C. Barbero, M.C. Miras, O. Haas, R. Kötz, J. Electrochem. Soc. 144 (1997) 4170, and reference therein.

15. G. Socrates, "Infrared Characteristic Group Frequencies", $2^{\text {nd }}$ Ed., J. Wiley \& Sons, Chichester, 1994.

16. S. Kunimura, T. Osaka, N. Oyama, Macromolecules 21 (1988) 894.

17. H. Salavagione, J. Arias, P. Garces, E. Morallon, C. Barbero, J.L. Vazquez, “81 Bunsen Kollokium”, Dresden, Sept 21-23, 2002; H.J. Salavagione, J. Arias, P. Garces, E. Morallon, C. Barbero, M.C. Miras, J.L. Vazquez, manuscript in preparation.

18. M.W. Urban, "Vibrational Spectroscopy of Molecules and Macromolecules on Surfaces", John Wiley \& Sons, New York, 1993, pp 233. 